\title{
Plasma and Urinary Calprotectin Levels in Type 2 Diabetic Patients with Peripheral Arterial Disease
}

\author{
Halawa M, Abushady MM, Abdelsalam Besibes MM, Basabbea AS, Mohamed NR \\ Department of Internal Medicine and Endocrinology, Faculty of Medicine - Ain Shams University, Cairo, Egypt
}

\begin{abstract}
Background: Plasma calprotectin is a persistent biomarker of insulin resistance (IR), gastroenteritis, and cardiovascular disease (CVD). We assessed the role of plasma and urinary calprotectin in type 2 diabetes patients with peripheral arterial disease (PAD), to assess whether calprotectin is a risk factor for developing PAD in type 2 diabetes patients.

Aim of the work: To study the association of plasma and urinary calprotectin levels with peripheral arterial disease in type 2 diabetic patients

Methods: The current study was conducted on 90 subjects. They were subdivided into 3 groups. Group I: 30 type 2 diabetics with PAD, group II: 30 type 2 diabetics without PAD and group III: 30 healthy control subjects of comparable age and sex. They were subjected to history taking, full clinical examination, anthropometric measurement, plasma and urinary calprotectin levels that were measured by ELISA and ankle brachial index. In addition, HbA1c, fasting serum lipid profile, highly sensitive CRP and CBC were measured.

Results: plasma calprotectin level was significantly higher in patients with T2DM with lower extremity peripheral arterial disease (LEPAD) compared to the other 2 groups, urinary calprotectin was significantly higher in all type 2 diabetic subjects compared to healthy control group. Age, current smoking status, duration of diabetes, glycated hemoglobin and plasma calprotectin were independent determinant of peripheral arterial disease in T2DM patients

Conclusion: Elevated plasma and urinary calprotectin levels in diabetic patients compared to healthy control suggest the possible role of calprotectin in development of atherosclerosis and peripheral arterial disease and the possibility of its use as a biomarker for diabetic vasculopathy.
\end{abstract}

Keywords: Plasma and urinary calprotectin, Type 2 diabetes mellitus, Peripheral arterial disease.

\section{INTRODUCTION}

The widespread prevalence of diabetes in many countries of the Middle East has made this region one of the incidence of diabetes in the world. Due to rapid socio-economic growth, changes in lifestyle, and increasing prevalence of obesity, the number of diabetics is expected to double by 2045 in this region ${ }^{(\mathbf{1})}$. Unfortunately, lower extremity peripheral arterial disease (LEPAD) is found asymptomatic in most people with diabetes and only $20 \%$ of them have symptoms associated with LEPAD ${ }^{(2)}$.

Diabetes significantly increases the risk of lower limb amputations, 10-20 times more than those without diabetes ${ }^{(3)}$. PAD causes significant long-term disability in patients with diabetes. Therefore, the treatment of patients with PAD may be costly due to the need for a variety of diagnostic tests, treatment procedures, and hospitalization $^{(4)}$.

Calprotectin has been recognized as an endogenous Toll-like receptor activator and as a glycation endproduct (RAGE) receptor. Calprotectin is thought to act as an intracellular differentiation marker for macrophages and as an extracellular protein complex (DAMP). Elevated plasma levels of calprotectin have been reported in a variety of chronic inflammatory conditions, including rheumatoid arthritis, allograft rejection, inflammatory bowel disease, cancer and lung disease. It is excreted during phagocytic stress. Elevated calprotectin levels have been reported to predict microvascular changes in patients with type diabetes 2 (T2DM). It was found to be an early and sensitive marker of acute coronary syndrome and non-fatal myocardial infarction. In an examination approach among healthy individuals, increased plasma concentrations of calprotectin were found to predict the risk of future cardiovascular events ${ }^{(5)}$.

Aim of the work was to study the association of plasma and urinary calprotectin levels with peripheral arterial disease in type 2 diabetic patients.

\section{PATIENTS AND METHODS}

A case control study conducted on 90 subjects divided into 60 type 2 diabetics recrurited from Endocrinology Clinic and Diabetic Foot Research Unit, Ain Shams University Hospital and 30 healthy control subjects. The 60 diabetic patients were subdivided into 2 groups.

Group I: 30 type 2 diabetics with peripheral arterial disease (15 females and 15 males) that was 
assessed either by history and foot examination for PAD. Also PAD was assessed by measuring anklebrachial index (ABI) using systolic blood pressure of brachial artery in each arm and systolic blood pressure in lower limb using ultrasonic pocket Doppler (Sonotrax, version 12, EDAN company, 01-5445540512) on the anterior tibial artery of each foot. The ABI of each leg is calculated by dividing the highest ankle SBP by the highest arm $\mathrm{SBP}^{(6)}$. A normal ABI is $1.0-1.1$. The $\mathrm{ABI}$ cut off $\leq 0.9$ was used to diagnose LEPAD.

Group II: 30 patients with T2DM without lower limb peripheral arterial disease ( 8 females and 22 males).

Group III: 30 healthy control subjects (13 females and 17 males) age and sex matched. They were collected from relatives and friends of the patients.

Exclusion criteria: included patients with history of ischemic heart disease, cerebrovascular accident, profound organ failure, history of malignancy or history of medications of rhumatological disease and pregnant women. The protocol for this study comply with the principles laid down in Declaration of Helsinki recommendations.

\section{Ethical approval:}

The study followed the ethical standards and was approved by the Ethical Committee of Ain Shams University. All subjects gave informed consent to participate in this study.

All participants were subjected to full medical history, thorough clinical examination including measurement of blood pressure, body weight, height and BMI $\left(\mathrm{kg} / \mathrm{m}^{2}\right)$.

\section{Laboratory studies:}

Plasma and urinary calprotectin were measured by sandwich ELISA. Other biochemical measurements: glycated hemoglobin by quantitative colorimetric method. Serum total cholesterol level, LDL cholesterol, serum triglycerides by enzyme colorimetric assay using commercially available kit. Complete blood count, urine analysis and highly sensitive CRP by ELISA were also measured.

\section{Statistical analysis}

Recorded data were analyzed using the statistical package for social sciences, version 20.0 (SPSS Inc., Chicago, Illinois, USA). Quantitative data were expressed as mean \pm standard deviation (SD). Qualitative data were expressed as frequency and percentage. Independentsamples t-test of significance was used when comparing between two means.

Chi-square $\left(\mathrm{x}^{2}\right)$ test of significance was used in order to compare proportions between two qualitative parameters. The confidence interval was set to $95 \%$ and the margin of error accepted was set to 5\%. The p-value was considered significant as the following:

- P-value <0.05 was considered significant.

- P-value <0.001 was considered as highly significant.

- P-value >0.05 was considered insignificant.

\section{RESULTS}

There was non-significant difference between the studied groups as regards sex $(\mathrm{P}>0.05)$. The mean age was significantly higher in type 2 diabetics with PAD compared to the other 2 groups $(58.63 \pm 8.48$ vs. 52.00 \pm 5.71 group II \& $55.30 \pm 5.42$ group III) $(\mathrm{p}<0.001)$. There was non-significant difference regarding smoking status between the studied groups $(\mathrm{P}=0.165)$. There was significant longer duration of diabetes on comparing type 2 diabetics with and without PAD (15.27 \pm 7.41 vs. $8.77 \pm 5.77$ years) ( $\mathrm{p}<0.001)$. Blood pressure was significantly higher on comparing type 2 diabetic patients without PAD versus healthy control group $(\mathrm{P}=0.006)$. BMI was significantly higher in type 2 diabetics with PAD compared to the other 2 groups consequently $(33.13 \pm 6.51$ vs. $28.48 \pm 4.77 \& 24.95 \pm 1.09)(\mathrm{p}<$ 0.001 ). There was non-significant difference regarding history of dyslipidemia between the studied groups $(\mathrm{P}=0.654)$.

There was highly significant difference $(\mathrm{p}<$ 0.001 ) between groups regarding glycated hemoglobin, LDL cholesterol and hs CRP. In addition, there was significant difference between groups regarding s. cr, s. total cholesterol and serum triglycerides $(\mathrm{P}<0.05)$. While there was no significant difference regarding white blood cell count $(\mathrm{P}>0.05)$ (Table 1$)$. 
Table (1): Comparison between data characteristics of all studied groups regarding laboratory data using ANOVA test.

\begin{tabular}{|c|c|c|c|c|c|c|c|c|}
\hline \multirow[b]{2}{*}{ Laboratory Data } & \multirow{2}{*}{$\begin{array}{l}\text { T2DM with } \\
\text { PAD }(\mathbf{N}=30)\end{array}$} & \multirow{2}{*}{$\begin{array}{c}\text { T2DM } \\
\text { without PAD } \\
(\mathrm{N}=30) \\
\end{array}$} & \multirow{2}{*}{$\begin{array}{l}\text { Healthy } \\
\text { Control } \\
(\mathrm{N}=\mathbf{3 0})\end{array}$} & \multirow{2}{*}{$\begin{array}{c}\text { ANOV } \\
\text { A }\end{array}$} & \multirow{2}{*}{$\begin{array}{c}\text { p- } \\
\text { value }\end{array}$} & \multicolumn{3}{|c|}{ Post HOC } \\
\hline & & & & & & P1 & $\mathbf{P 2}$ & P3 \\
\hline $\begin{array}{l}\text { Fasting blood glucose } \\
(\mathbf{m g} / \mathbf{d l}) \\
\text { Mean } \pm \text { SD }\end{array}$ & $188.90 \pm 6.26$ & $150.17 \pm 33.72$ & $91.70 \pm 10.73$ & 38.19 & $<0.001$ & 0.003 & $<0.001$ & $<0.001$ \\
\hline $\begin{array}{l}\text { Glycated hemoglobin } \\
\text { A1C }(\%) \\
\text { Mean } \pm \text { SD }\end{array}$ & $8.54 \pm 0.84$ & $7.99 \pm 0.69$ & $5.04 \pm 0.56$ & 215.02 & $<0.001$ & 0.003 & $<0.001$ & $<0.001$ \\
\hline $\begin{array}{ll}\text { Serum } & \text { creatinine } \\
(\mathbf{m g} / \mathbf{d l}) & \\
\text { Mean } \pm \text { SD } & \\
\text { Range } & \end{array}$ & $\begin{array}{l}0.91 \pm 0.16 \\
0.6-1.4\end{array}$ & $\begin{array}{l}0.89 \pm 0.16 \\
0.5-1.3\end{array}$ & $\begin{array}{l}0.83 \pm 0.12 \\
0.6-1\end{array}$ & 2.99 & 0.045 & 0.762 & 0.054 & 0.027 \\
\hline $\begin{array}{ll}\text { Total } & \text { cholesterol } \\
(\mathbf{m g} / \mathbf{d l}) & \\
\text { Mean } \pm \mathrm{SD} & \\
\text { Range } & \end{array}$ & $\begin{array}{l}228.73 \pm 47.57 \\
154-347 \\
\end{array}$ & $\begin{array}{l}222.43 \pm 40.80 \\
180-323\end{array}$ & $\begin{array}{l}203.53 \pm 25.71 \\
178-261\end{array}$ & 3.37 & 0.039 & 0.534 & 0.014 & 0.065 \\
\hline $\begin{array}{l}\text { LDLc (mg/dl) } \\
\text { Mean } \pm \text { SD } \\
\text { Range }\end{array}$ & $\begin{array}{l}131.63 \pm 28.57 \\
73-180\end{array}$ & $\begin{array}{l}116.00 \pm 21.97 \\
75-150\end{array}$ & $\begin{array}{l}109.50 \pm 9.45 \\
99-127 \\
\end{array}$ & 8.39 & $<0.001$ & 0.006 & $<0.001$ & 0.245 \\
\hline $\begin{array}{l}\text { HDLc }(\mathbf{m g} / \mathbf{d l}) \\
\text { Mean } \pm \text { SD } \\
\text { Range }\end{array}$ & $\begin{array}{l}42.40 \pm 7.81 \\
30-57 \\
\end{array}$ & $\begin{array}{l}41.83 \pm 9.00 \\
25-56\end{array}$ & $\begin{array}{l}43.30 \pm 6.45 \\
30-58\end{array}$ & 0.27 & 0.765 & 0.780 & 0.657 & 0.470 \\
\hline $\begin{array}{l}\text { Triglyceride }(\mathbf{m g} / \mathbf{d l}) \\
\text { Mean } \pm \text { SD }\end{array}$ & $181.23 \pm 7.69$ & $165.50 \pm 6.22$ & $140.80 \pm 5.85$ & 4.23 & 0.018 & 0.265 & 0.005 & 0.082 \\
\hline $\begin{array}{l}\text { White blood cell count } \\
\text { Mean } \pm \text { SD }\end{array}$ & $6463.33 \pm 988.67$ & $6360.00 \pm 792.82$ & $6670.00 \pm 603.69$ & 0.23 & 0.795 & 0.825 & 0.658 & 0.507 \\
\hline $\begin{array}{l}\text { hsCRP (mg/L) by } \\
\text { ELISA } \\
\text { Mean } \pm \text { SD } \\
\text { Range }\end{array}$ & $\begin{array}{l}13.05 \pm 2.22 \\
0-17\end{array}$ & $\begin{array}{l}12.36 \pm 1.57 \\
-15\end{array}$ & $\begin{array}{l}4.60 \pm 1.53 \\
.5-8\end{array}$ & 203.21 & $<0.001$ & 0.140 & $<0.001$ & $<0.001$ \\
\hline
\end{tabular}

P1: Comparison between T2DM with and without PAD; P2: Comparison between T2DM with PAD and healthy control; P3: Comparison between T2DM without PAD and healthy control. BMI:body mass index.

F- ANOVA test; $P$-value $<0.05$ significant; $p$-value $<0.001$ highly significant; $\mathrm{p}$-value $>0.05$ no significant

There was highly significant elevation of plasma calprotectin level $(\mathrm{P}<0.001)$ in type 2 diabetics with PAD compared to the other groups. Urinary calprotectin was significantly higher on comparing type 2 diabetics with and without PAD vs healthy control $(\mathrm{p}<0.001)$ (Table 2$)$.

Table (2): Comparison between the studied groups as regard plasma and urinary calprotectin level.

\begin{tabular}{|c|c|c|c|c|c|c|c|c|}
\hline \multirow[b]{2}{*}{ Calprotectin } & \multirow{2}{*}{$\begin{array}{l}\text { T2DM with } \\
\text { PAD }(\mathbf{N}=30)\end{array}$} & \multirow{2}{*}{$\begin{array}{c}\text { T2DM } \\
\text { without } \\
\text { PAD }(\mathrm{N}=30) \\
\end{array}$} & \multirow{2}{*}{$\begin{array}{c}\text { Healthy } \\
\text { Control } \\
(\mathbf{N}=\mathbf{3 0})\end{array}$} & \multirow[b]{2}{*}{ ANOVA } & \multirow{2}{*}{$\begin{array}{c}\text { p- } \\
\text { value }\end{array}$} & \multicolumn{3}{|c|}{ Post HOC } \\
\hline & & & & & & P1 & $\mathbf{P 2}$ & P3 \\
\hline \multirow{3}{*}{$\begin{array}{l}\text { Plasma calprotectin level } \\
(\mathbf{p g} / \mathrm{ml}) \\
\text { Mean } \pm \mathrm{SD} \\
\text { Range }\end{array}$} & & & & & & & & \\
\hline & $447.40 \pm 100.40$ & $365.67 \pm 76.22$ & $255.80 \pm 75.59$ & 3851 & $<0,001$ & $<0$ & $<0$ & $<0001$ \\
\hline & $340-715$ & $220-515$ & $118-410$ & 38.51 & $<0.001$ & $<0.001$ & $<0.001$ & $<0.001$ \\
\hline \multirow{3}{*}{$\begin{array}{l}\text { Urinary calprotectin level } \\
(\mathbf{p g} / \mathbf{m l}) \\
\text { Mean } \pm \mathrm{SD} \\
\text { Range }\end{array}$} & & & & & & & & \\
\hline & $322.30 \pm 43.36$ & $322.20 \pm 48.35$ & $215.30 \pm 37.88$ & 60.71 & $<0.001$ & 0.993 & $<0.001$ & $<0.001$ \\
\hline & 240-390 & 218-410 & $150-290$ & & & & & \\
\hline
\end{tabular}

In multivariable regression analysis; age (odds ratio (OR) 1.3, p 0.001), current smoking status (OR 26.60, P 0.04), BMI (OR 1.21, P 0.003), duration of diabetes mellitus (OR 1.73, P 0.001), fasting blood glucose (OR 1.01, P 0.006), glycated hemoglobin (OR 2.74, P 0.008) and plasma calprotectin were independent determinant of peripheral arterial disease in T2DM patients (Table 3). 
The cut-off value of plasma calprotectin to predict peripheral arterial disease in those with PAD versus healthy control group was $>330 \mathrm{pg} / \mathrm{ml}$ with a sensitivity of $100 \%$, a specificity of $90 \%$, positive predictive value (PPV) of $90.9 \%$, negative predictive value (NPV) of $100 \%$ and accuracy of $95 \%$. The cut-off of urinary calprotectin to predict peripheral arterial disease in type 2 diabetics with PAD versus healthy control group was $>228 \mathrm{pg} / \mathrm{ml}$ with a sensitivity of $100 \%$, a specificity of $80 \%$, positive predictive value (PPV) of $83.3 \%$, negative predictive value (NPV) of $100 \%$ and accuracy of $96 \%$.

Table (3): Multivariable regression analysis of independent variables of PAD in T2DM

\begin{tabular}{|l|c|c|c|c|}
\hline \multicolumn{1}{|c|}{ Variables } & Odds Ratio & p value & \multicolumn{2}{c|}{ (95\% Conf. } \\
\hline Age (years) & 1.13 & $\mathbf{0 . 0 0 1}$ & 2.9 & 10.4 \\
\hline Sex & 2.55 & 0.089 & 0.0 & 0.5 \\
\hline Current smoking status & 26.60 & $\mathbf{0 . 0 4}$ & 0.0 & 0.4 \\
\hline History of hypertension & 0.48 & 0.068 & -0.4 & 0.0 \\
\hline History of dyslipidemia & 3.70 & 0.523 & -0.3 & 0.2 \\
\hline Body mass index (BMI) kg/m & 1.21 & $\mathbf{0 . 0 0 3}$ & 1.7 & 7.6 \\
\hline Presence of Peripheral Neuropathy & 3.634 & $\mathbf{0 . 0 3 0}$ & 2.653 & 4.833 \\
\hline Duration of diabetes mellitus & 1.73 & $<\mathbf{0 . 0 0 1}$ & 3.1 & 9.9 \\
\hline Treatment of diabetes mellitus & 3.10 & 0.121 & -0.1 & 0.7 \\
\hline Fasting blood glucose mg/dl & 1.01 & $\mathbf{0 . 0 0 6}$ & 11.6 & 65.9 \\
\hline Glycated hemoglobin (A1C) & 2.74 & $\mathbf{0 . 0 0 8}$ & 0.2 & 0.9 \\
\hline Serum creatinine mg/dl & 0.06 & 0.782 & -0.1 & 0.1 \\
\hline Total cholesterol mg/dl & 0.98 & 0.584 & -16.6 & 29.2 \\
\hline Low Density Lipoprotein mg/dl & 1.05 & $\mathbf{0 . 0 2 1}$ & 2.5 & 28.8 \\
\hline High Density Lipoprotein mg/dl & 1.06 & 0.795 & -3.8 & 4.9 \\
\hline Triglyceride mg/dl & 0.98 & 0.298 & -14.3 & 45.7 \\
\hline White blood cell count & 1.00 & 0.833 & -875.2 & 1081.9 \\
\hline hsCRP mg/L by ELISA & 1.24 & 0.168 & -0.3 & 1.7 \\
\hline Plasma calprotectin level & 1.03 & $\mathbf{0 . 0 0 1}$ & 35.7 & 127.8 \\
\hline Urinary calprotectin level & 0.97 & 0.993 & -23.6 & 23.8 \\
\hline
\end{tabular}

\section{DISCUSSION}

To best of our knowledge, our study is the first study describing the correlation between calprotectin (plasma and urinary) concentrations and lower extremities peripheral arterial disease (LEPAD) in type 2 diabetic patients.

Our study showed that the mean of plasma calprotectin level was significantly higher in type 2 diabetics with PAD by about $45 \%$ compared to those without PAD and to healthy control group by about $75 \%$ as well. This comes in agreement with Ortega et al. ${ }^{(8)}$ who found increased level of calprotectin associated with atherosclerosis in type 2 diabetic patients. Peng $\boldsymbol{e t}$ al. ${ }^{(7)}$ conducted his study in Shanghai, which included 375 type 2 diabetes participants with and without coronary artery disease (CAD). The mean age of those with type 2 diabetics and CAD was $68.63 \pm 10$ years. They did carotid ultrasound for those without CAD and reported that the level of plasma calprotectin was elevated in type 2 diabetics with CAD and its level was positively correlated with severity of CAD. In those without clinically overt CAD, the plasma level of calprotectin was positively correlated with carotid intima media thickness.
In our study, the mean of urinary calprotectin level was higher in type 2 diabetic patients with PAD and without PAD compared to healthy control group. This finding was in agreement with Ortega et al. ${ }^{(8)}$.

Our study showed that there was no association between plasma calprotectin in type 2 diabetics with PAD and age. This is in agreement with Sekimoto et al. (9). Providing normal renal function, this finding will pave the way to set one plasma calprotectin cut-off for all age groups, but large study is required to prove this. In contrast, Cotoi et al. ${ }^{(10)}$ found that high plasma calprotectin level was associated with age.

In our study, advanced age was a significant predictor for PAD among T2DM. This finding is in agreement with Eltoony et al. ${ }^{(11)}$. However, our finding is inconsistent with Alzahrani $\boldsymbol{e t}$ al. ${ }^{(12)}$ who found no association between old age and PAD among patients with T2DM in Saudi participants.

In the receiver operating characteristics analysis ROC analysis, the area under the curve (AUC) was 0.95, which reflects the accuracy of the calprotectin as a diagnostic biomarker for PAD in type 2 diabetics. Peng et al. ${ }^{(7)}$ found that AUC for plasma calprotectin was limited (only 0.63 ) for the diagnosis of coronary artery 
disease and was not superior to that of hsCRP in their study. They attributed this to anti-lipid medications, which was used by a small number of the patients. The pathogenesis of PAD is not identical to that of coronary arteries where inflammation is more dominant in PAD (13). In (ROC) the area under the curve was 0.96, which reflect the accuracy of the urinary calprotectin as a diagnostic biomarker for LEPAD in T2DM.

In our study, multivariable regression analysis for independent variables in type 2 diabetics with PAD revealed that plasma calprotectin level was a significant laboratory predictor of PAD in type 2 diabetic patients. Furthermore, advanced age, current smoking status, body mass index were significant clinical predictors for PAD in type 2 diabetic patients.

\section{CONCLUSION}

Plasma calprotectin was high in T2DM with PAD. Urinary calprotectin level in T2DM with PAD was similar to T2DM without PAD. Plasma calprotectin was independent determinant of PAD in T2DM, suggesting the possible role of calprotectin in development of atherosclerosis and peripheral arterial disease and the possibility of its use as a biomarker for diabetic vasculopathy.

Conflict of interest: The authors declare no conflict of interests.

Funding: There was no financial funding from any institution.

\section{REFERENCES}

1. Al Busaidi N, Shanmugam P, Manoharan F (2019): Diabetes in the Middle East: Government Health Care Policies and Strategies that Address the Growing Diabetes Prevalence in the Middle East. Springer Science, Current Diabetes Report, 19: 8-12.

2. McGuire D, Marx N (2015): Diabetes in cardiovascular disease: a companion to Braunwald's heart disease; A Companion to Braunwald's Heart Disease. First edition. Elsevier Saundars, Pp: 349-60.

3. World Health Organization (2016): Global Report on Diabetes.

https://www.researchgate.net/publication/312383296_WH

O_Global_report_on_diabetes_A_summary
4. Hirsch A, Haskal Z, Hertzer $\mathbf{N}$ et al. (2005): Practice Guidelines for the management of patients with peripheral arterial disease (lower extremity, renal, mesenteric, and abdominal aortic): a collaborative report from the American Association for Vascular Surgery/Society for Vascular Surgery. Circulation, 113: 463-54.

5. Pedersen L, Nybo M, Poulsen M et al. (2014): Plasma calprotectin and its association with cardiovascular disease manifestations, obesity and the metabolic syndrome in type 2 diabetes mellitus patients. BMC Cardiovascular Disorders, 14: 196-203.

6. Polonsky WH, Jelsovsky Z, Panzera S et al. (2009): Primary care physicians identify and act upon glycemic abnormalities found in structured, episodic blood glucose monitoring data from non-insulin-treated type 2 diabetes. Diabetes Technol Ther., 11: 283-291.

7. Peng W, Jian W, Li H et al. (2011): Increased serum myeloid-related protein $8 / 14$ level is associated with atherosclerosis in type 2 diabetic patients. Cardiovascular Diabetology, 10: 1-7.

8. Ortega F, Sabater M, Moreno-Navarrete J et al. (2012): Serum and urinary concentrations of calprotectin as markers of insulin resistance and type 2 diabetes. European Journal of Endocrinology, 167: 569-78.

9. Sekimoto R, Kishida K, Nakatsuji H et al. (2012): High circulating levels of S100A8/A9 complex (calprotectin) in male Japanese with abdominal adiposity and dysregulated expression of S100A8 and S100A9 in adipose tissues of obese mice. Biochemical and Biophysical Research Communications, 419: 782-9.

10. Cotoi S, Dunér P, Ko N et al. (2014): Plasma S100A8/A9 Correlates With Blood Neutrophil Counts, Traditional Risk Factors, and Cardiovascular Disease in Middle-Aged Healthy Individuals. Arterioscler Thromb Vasc Biol., 34: 202-10.

11. Eltoony L, Thabet A, Abdel-wahab L et al. (2015): Risk Factors of Peripheral Vascular Disease in Diabetic Patients at Assiut University Hospitals. Med J Cairo Univ., 82: 5360.

12. Alzahrani H, Wang D, Bakhotmah B et al. (2014): Risk factors for peripheral arterial disease among patients with diabetes mellitus in Saudi Arabia. Vasc Med., 19: 103-11.

13. Tunstall-Pedoe H, Peters S, Woodward $M$ et al. (2017): Twenty-Year Predictors of Peripheral Arterial Disease Compared With Coronary Heart Disease in the Scottish Heart Health Extended Cohort (SHHEC). Journal of the American Heart Association, 117: 1-19. 